\title{
Creating Recoverable Mechanoluminescence in Piezoelectric Calcium Niobates through $\mathrm{Pr}^{3+}$ Doping
}

Jun-Cheng Zhang, ${ }^{*,}$ Yun-Ze Long, ${ }^{\dagger}$ Xu Yan, ${ }^{\dagger}$ Xusheng Wang, ${ }^{\S}$ and Feng Wang ${ }^{*,+, \Perp}$

${ }^{\dagger}$ College of Physics, Qingdao University, Qingdao 266o71, P. R. China

${ }^{\ddagger}$ Department of Physics and Materials Science, City University of Hong Kong, 83 Tat Chee Avenue, Hong Kong SAR, P. R. China

${ }^{\S}$ Functional Materials Research Laboratory, Tongji University, Shanghai 201804, P. R. China

"City University of Hong Kong Shenzhen Research Institute, Shenzhen 518057, P. R. China

Corresponding Authors

*E-mail: jc-zhang@qdu.edu.cn; zhangjuncheng584@163.com

*E-mail: fwang24@cityu.edu.hk 


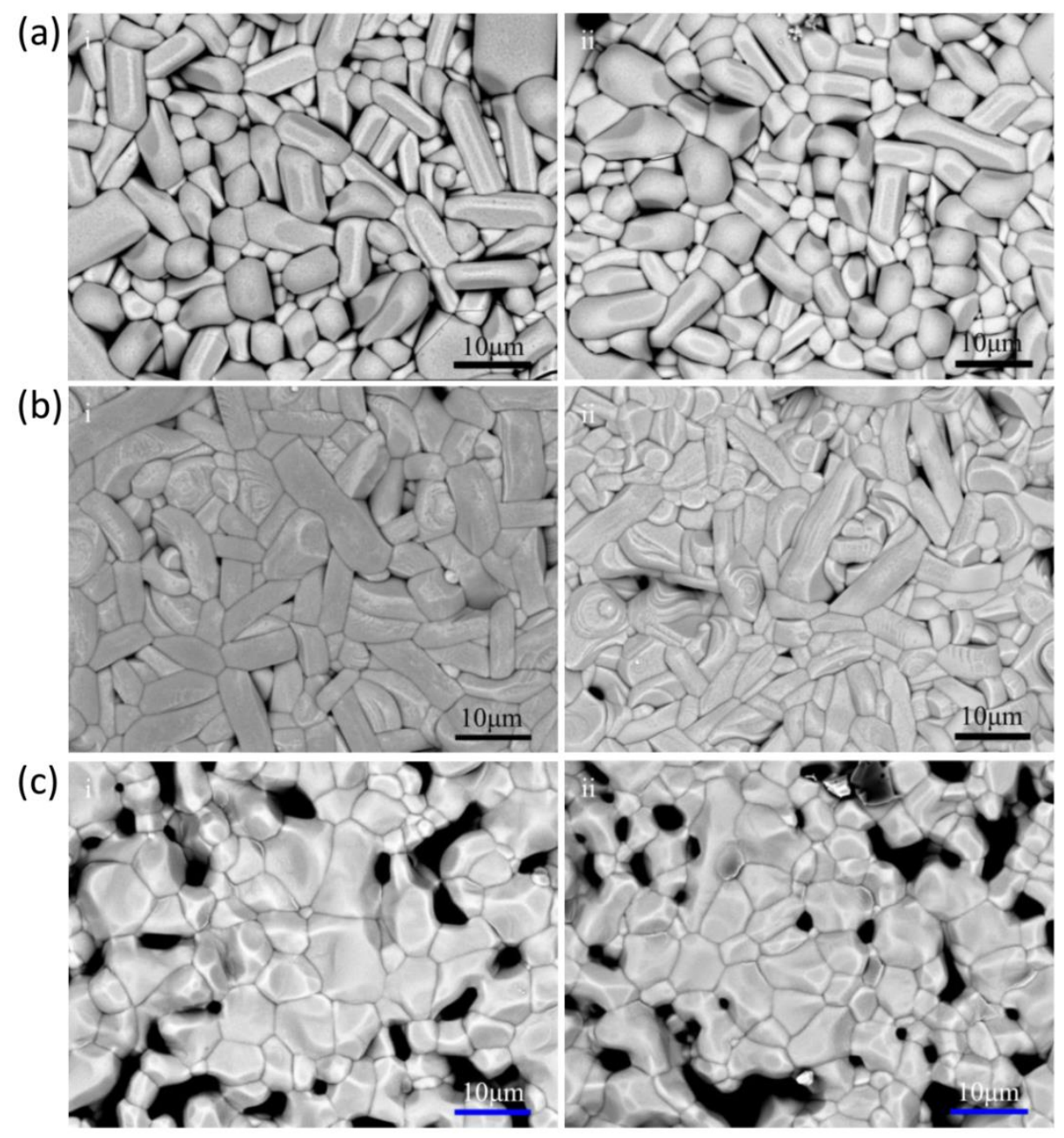

Figure S1. Representative SEM images of the sintered pellets of calcium niobates. (a-i) $\mathrm{CaNb}_{2} \mathrm{O}_{6}$ and (a-ii) $\mathrm{CaNb}_{2} \mathrm{O}_{6}: \mathrm{Pr}^{3+}$ (o.25 mol\%); (b-i) $\mathrm{Ca}_{2} \mathrm{Nb}_{2} \mathrm{O}_{7}$ and (b-ii) $\mathrm{Ca}_{2} \mathrm{Nb}_{2} \mathrm{O}_{7}: \mathrm{Pr}^{3+}$ (o.1 mol\%); (c-i) $\mathrm{Ca}_{3} \mathrm{Nb}_{2} \mathrm{O}_{8}$ and (c-ii) $\mathrm{Ca}_{3} \mathrm{Nb}_{2} \mathrm{O}_{8}: \mathrm{Pr}^{3+}$ (o.o75 mol\%). 

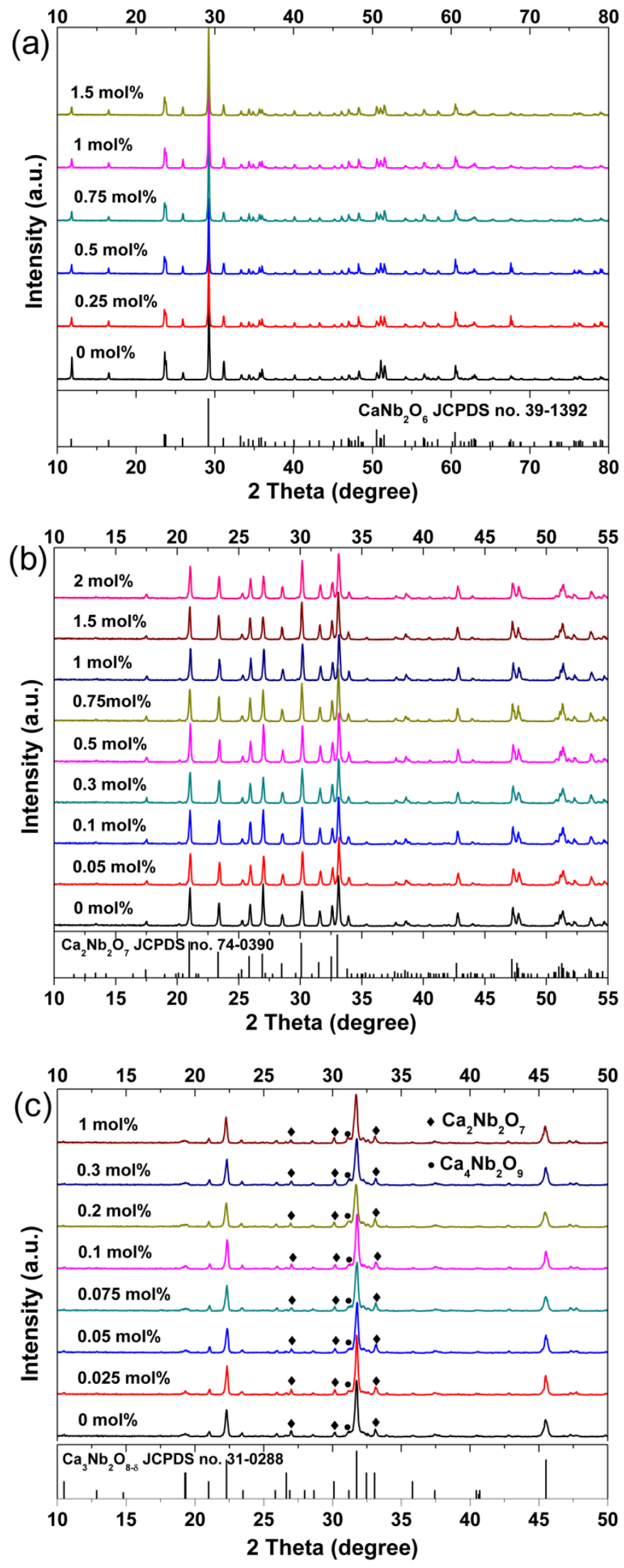

Figure S2. Powder XRD patterns of (a) $\mathrm{CaNb}_{2} \mathrm{O}_{6}: \mathrm{Pr}^{3+}$ (o-1.5 mol\%), (b) $\mathrm{Ca}_{2} \mathrm{Nb}_{2} \mathrm{O}_{7}: \mathrm{Pr}^{3+}(\mathrm{o}-2 \mathrm{~mol} \%$ ), and (c) $\mathrm{Ca}_{3} \mathrm{Nb}_{2} \mathrm{O}_{8}: \mathrm{Pr}^{3+}$ (o-1 mol\%). 
(a)

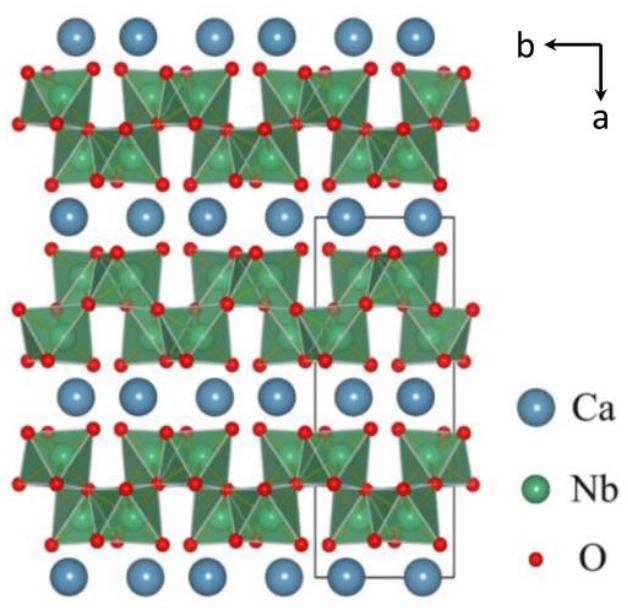

(b) $\quad \mathrm{Ca}_{2} \mathrm{Nb}_{2} \mathrm{O}_{7}$

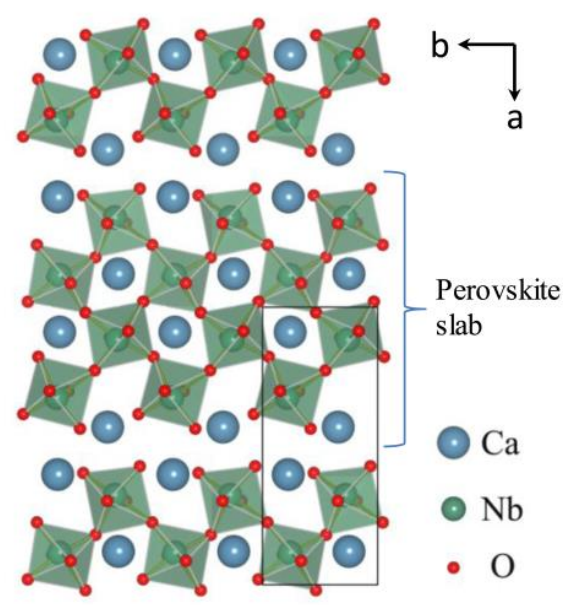

Figure $\mathrm{S}_{3}$. Crystal structures of (a) $\mathrm{CaNb}_{2} \mathrm{O}_{6}$ and (b) $\mathrm{Ca}_{2} \mathrm{Nb}_{2} \mathrm{O}_{7} \cdot \mathrm{CaNb}_{2} \mathrm{O}_{6}$ has a columbite structure with lattice parameters $a=14.926 \AA, b=5.752 \AA, c=5.204 \AA, V=446.79 \AA^{3}$, and $Z=4$. The structure can be described as a network of $\mathrm{NbO}_{6}$ octahedra sharing edges with two other ones to form chains running along the $c$-axis. The $\mathrm{Ca}^{2+}$ ions are surrounded by eight oxygen atoms in a distorted cubic geometry. $\mathrm{Ca}_{2} \mathrm{Nb}_{2} \mathrm{O}_{7}$ has a monoclinic structure with unit cell dimensions of $a=13.385 \AA, b=5.502 \AA, c=7.697 \AA$, and $\beta=98.34^{\circ}$. The crystal is constructed from slabs of a perovskite-type structure with a thickness corresponding to twice the face diagonal of the perovskite cube. 

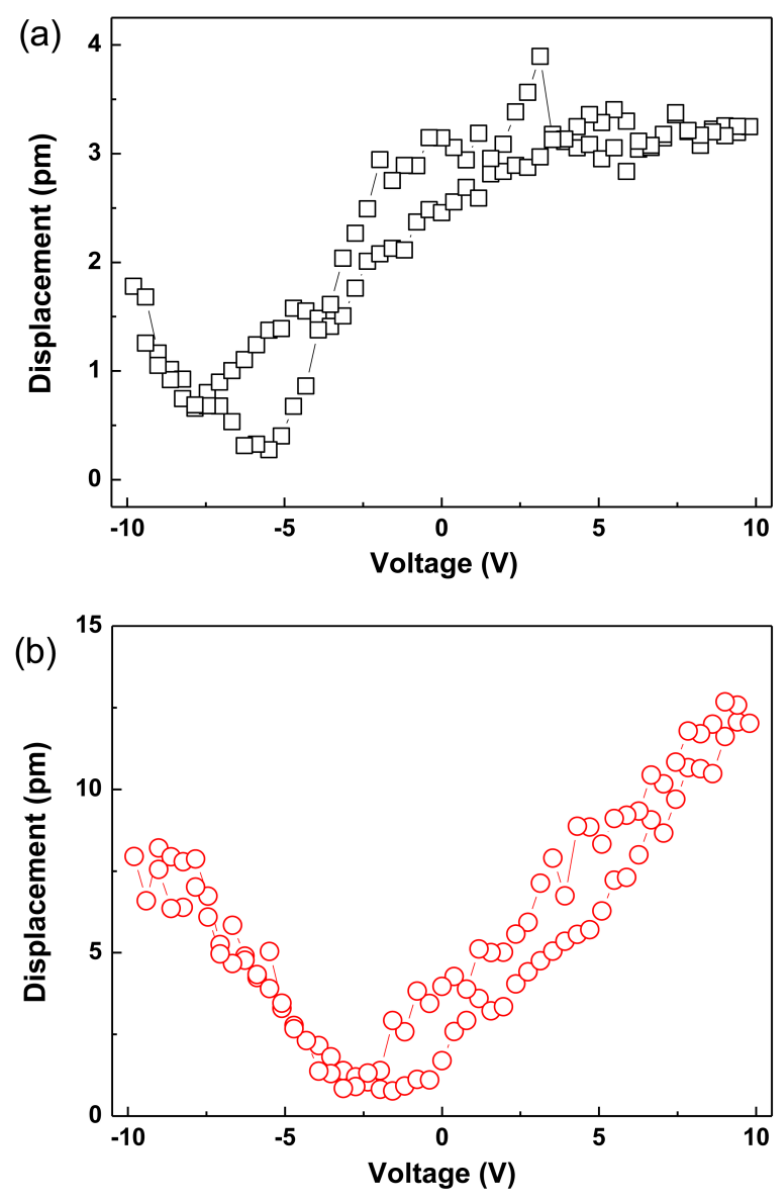

Figure $\mathrm{S}_{4}$. PFM measurements of the individual grain on ceramic pellets. (a) $\mathrm{CaNb}_{2} \mathrm{O}_{6}: \mathrm{Pr}^{3+}(0.25$ mol\%), showing a weak piezoelectricity. (b) $\mathrm{Ca}_{2} \mathrm{Nb}_{2} \mathrm{O}_{7}: \mathrm{Pr}^{3+}$ (o.1 mol\%). The piezoelectric constant $d_{33}$ of $\mathrm{Ca}_{2} \mathrm{Nb}_{2} \mathrm{O}_{7}: \mathrm{Pr}^{3+}$ was estimated to be $\sim 13 \mathrm{pm} \mathrm{V}^{-1}$. Note that the PFM measurement on the sintered $\mathrm{Ca}_{3} \mathrm{Nb}_{2} \mathrm{O}_{8}: \mathrm{Pr}^{3+}$ pellets was unsuccessful due to the porous structure (see Fig. $\mathrm{S} 1$ ). 

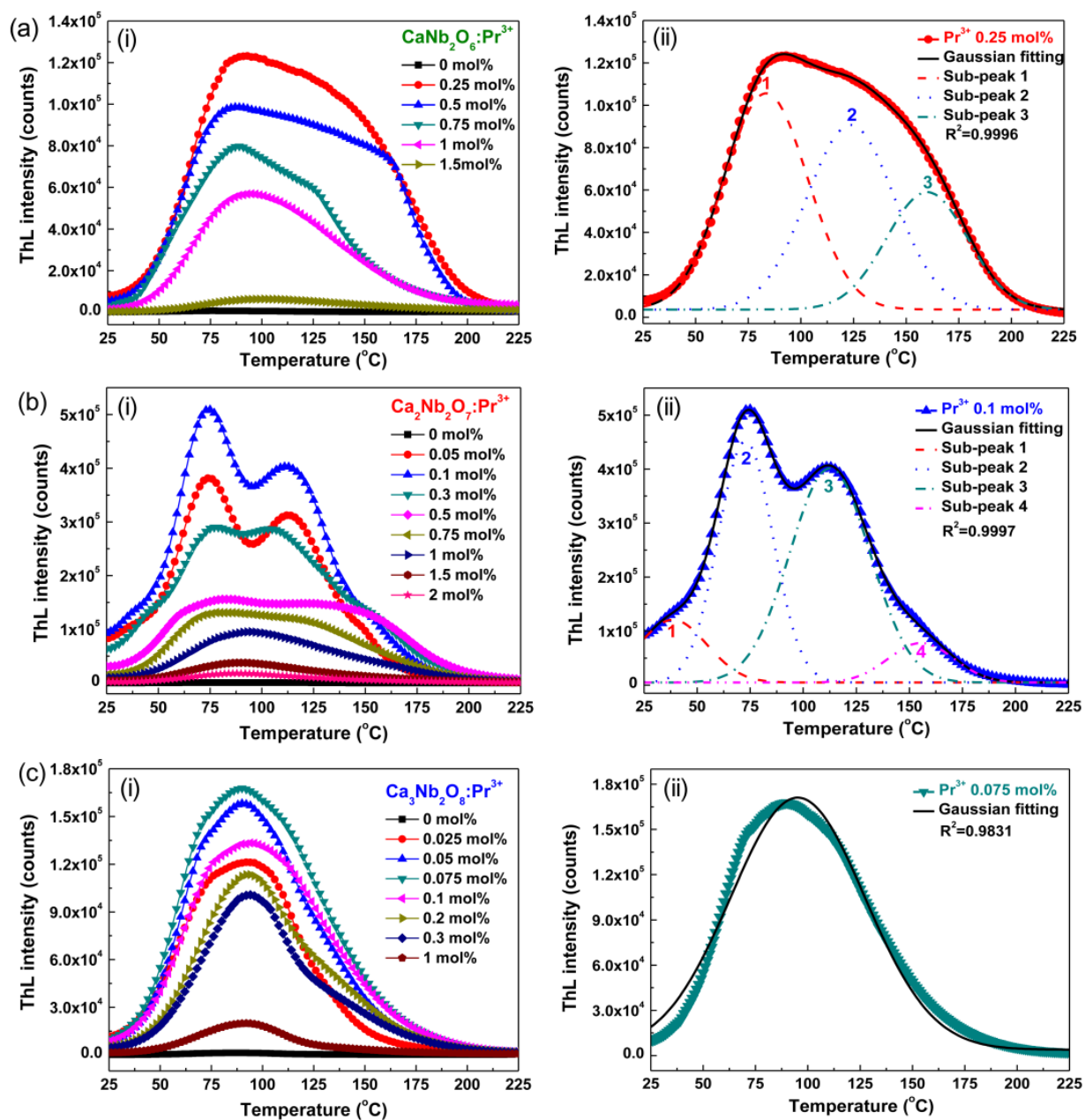

Figure $\mathrm{S}_{5}$. ThL curves of the calcium niobates comprising different concentrations of $\operatorname{Pr}^{3^{3+}}$. (a-i) $\mathrm{CaNb}_{2} \mathrm{O}_{6}: \mathrm{Pr}^{3+}$ (o-1.5 mol\%); (b-i) $\mathrm{Ca}_{2} \mathrm{Nb}_{2} \mathrm{O}_{7}: \mathrm{Pr}^{3+}$ (o-2 mol\%); (c-i) $\mathrm{Ca}_{3} \mathrm{Nb}_{2} \mathrm{O}_{8}: \mathrm{Pr}^{3+}$ (o-1 mol\%). The results indicate that the ThL intensity is strongly dependent on the concentration of $\mathrm{Pr}^{3^{+}}$ dopants. The similar ThL profiles suggest the existence of the same kind of traps in each system. Gaussian deconvolution of the ThL peaks. (a-ii) $\mathrm{CaNb}_{2} \mathrm{O}_{6}: \mathrm{Pr}^{3+}$ (o.25 mol\%); (b-ii) $\mathrm{Ca}_{2} \mathrm{Nb}_{2} \mathrm{O}_{7}: \mathrm{Pr}^{3+}$ (o.1 mol\%); (c-ii) $\mathrm{Ca}_{3} \mathrm{Nb}_{2} \mathrm{O}_{8}: \mathrm{Pr}^{3+}$ (o.o75 mol\%).

Table S1. Estimated trap depth $\left(E_{\mathrm{t}}\right)$ of the individual ThL sub-peak. ${ }^{1}$

\begin{tabular}{ccccc}
\hline Samples & Peak 1 & Peak 2 & Peak 3 & Peak 4 \\
& $\boldsymbol{E}_{\mathbf{t}}(\mathbf{e V})$ & $\boldsymbol{E}_{\mathbf{t}}(\mathbf{e V})$ & $\boldsymbol{E}_{\mathbf{t}}(\mathbf{e V})$ & $\boldsymbol{E}_{\mathbf{t}}(\mathbf{e V})$ \\
\hline $\mathrm{CaNb}_{2} \mathrm{O}_{6}: \operatorname{Pr}^{3+}(0.25 \mathrm{~mol} \%)$ & 0.71 & 0.81 & 1.04 & - \\
$\mathrm{Ca}_{2} \mathrm{Nb}_{2} \mathrm{O}_{7}: \operatorname{Pr}^{3+}(0.1 \mathrm{~mol} \%)$ & 0.60 & 0.89 & 1.03 & 1.27 \\
$\mathrm{Ca}_{3} \mathrm{Nb}_{2} \mathrm{O}_{8}: \mathrm{Pr}^{3+}(0.075 \mathrm{~mol} \%)$ & 0.74 & - & - & - \\
\hline
\end{tabular}




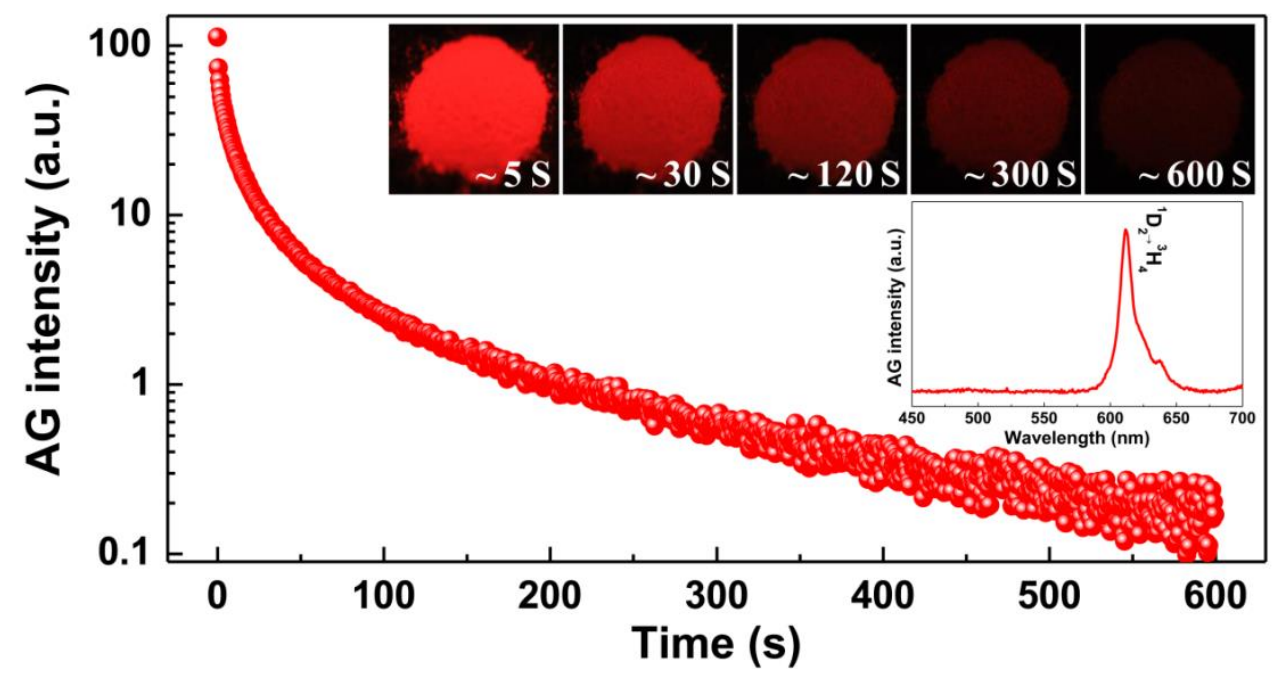

Figure S6. AG decay curve of $\mathrm{Ca}_{2} \mathrm{Nb}_{2} \mathrm{O}_{7}: \mathrm{Pr}^{3+}$ (o.1 mol\%). The insets show spectrum of the persistent luminescence and optical images taken at different times (5-6oo s) after irradiating the sample by $254 \mathrm{~nm}$ UV light for $1 \mathrm{~min}$. The red persistent luminescence is visible to the naked eye for more than $600 \mathrm{~s}$. 


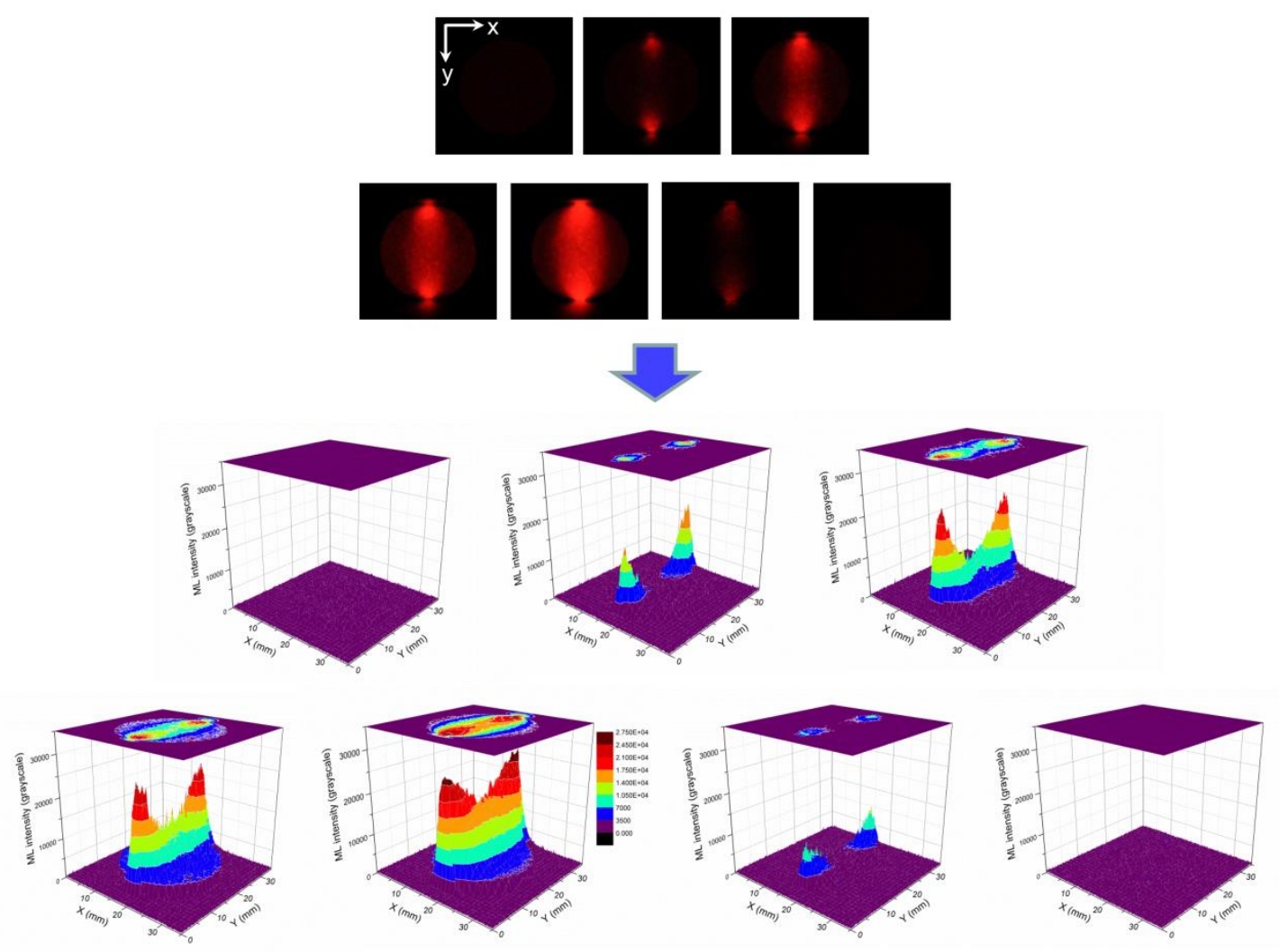

Figure $\mathrm{S}_{7}$. 3D distribution of relative ML intensity by extracting the brightness derived from the transient ML images during the compressing-releasing process. 

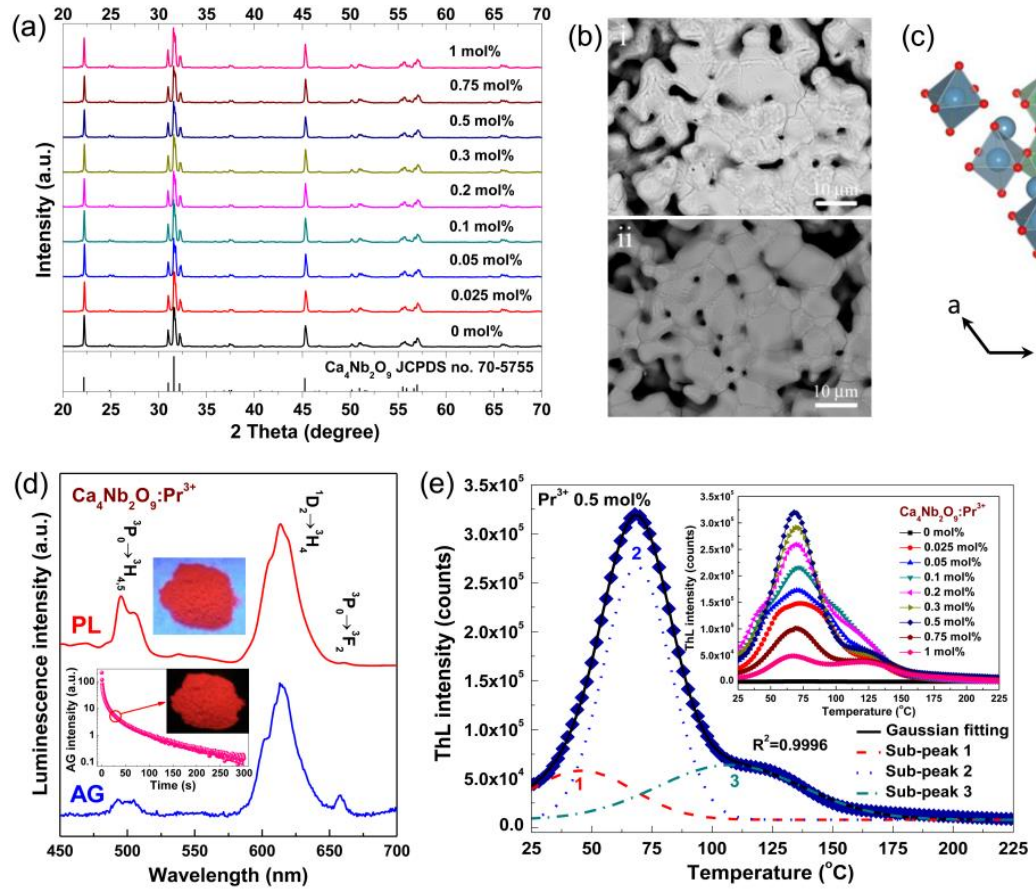

(c)

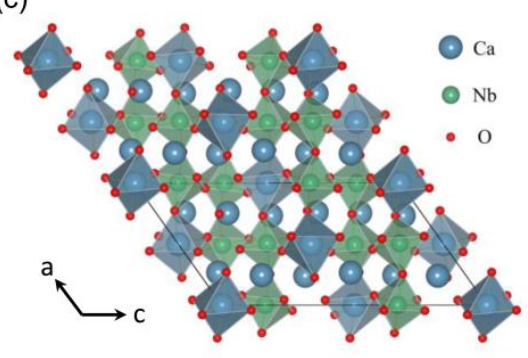

Figure S8. Characterizations of the $\mathrm{Pr}^{3+}$ activated $\mathrm{Ca}_{4} \mathrm{Nb}_{2} \mathrm{O}_{9}$. (a) XRD patterns of $\mathrm{Ca}_{4} \mathrm{Nb}_{2} \mathrm{O}_{9}: \mathrm{Pr}^{3+}$ (o-1 mol\%) showing a single monoclinic phase of all the samples. (b) SEM images of the sintered pellets: (b-i) $\mathrm{Ca}_{4} \mathrm{Nb}_{2} \mathrm{O}_{9}$; (b-ii) $\mathrm{Ca}_{4} \mathrm{Nb}_{2} \mathrm{O}_{9}: \mathrm{Pr}^{3+}$ (o.5 mol\%). (c) Crystal structure of $\mathrm{Ca}_{4} \mathrm{Nb}_{2} \mathrm{O}_{9}$ with a 2:1 ordering of $\mathrm{Ca}$ and $\mathrm{Nb}$ cations and lattice parameters $a=9.816 \AA, b=5.536 \AA, c=17.350 \AA$, and $\beta=125.5^{\circ} .^{2}$ The crystallographically distinct $\left[\mathrm{NbO}_{6}\right]$ octahedra are vertex-linked simultaneously to $\left[\mathrm{CaO}_{6}\right]$ and other $\left[\mathrm{NbO}_{6}\right]$ octahedral, while the $\left[\mathrm{CaO}_{6}\right]$ octahedra are connected exclusively to $\left[\mathrm{NbO}_{6}\right]$ octahedral. The $P_{2_{1}} / c$ space group belongs to the centrosymmetric class $2 / m$, suggesting the absence of piezoelectricity. (d) PL ( $\lambda_{\mathrm{ex}}=316 \mathrm{~nm}$ ) and AG spectra of $\mathrm{Ca}_{4} \mathrm{Nb}_{2} \mathrm{O}_{9}: \mathrm{Pr}^{3+}$ (0.5 mol\%). Insets are PL optical image, AG decay curve, and AG image (taken at $\sim 30 \mathrm{~s}$ after irradiation). (e) Gaussian deconvolution of the ThL peak of $\mathrm{Ca}_{4} \mathrm{Nb}_{2} \mathrm{O}_{9}: \mathrm{Pr}^{3+}$ (o.5 mol\%). Sub-peak 1 corresponding to trap depth $0.51 \mathrm{eV}$ is responsible for the persistent luminescence. Inset shows the ThL curve of $\mathrm{Ca}_{4} \mathrm{Nb}_{2} \mathrm{O}_{9}: \mathrm{Pr}^{3+}$ comprising different concentrations of $\mathrm{Pr}^{3^{+}}$. (f) Schematic illustration of indirect coupling between trap and higher-lying state of $\mathrm{Pr}^{3+}$ through charge transfer state in the $\mathrm{Ca}_{4} \mathrm{Nb}_{2} \mathrm{O}_{9}: \mathrm{Pr}^{3+}$. 

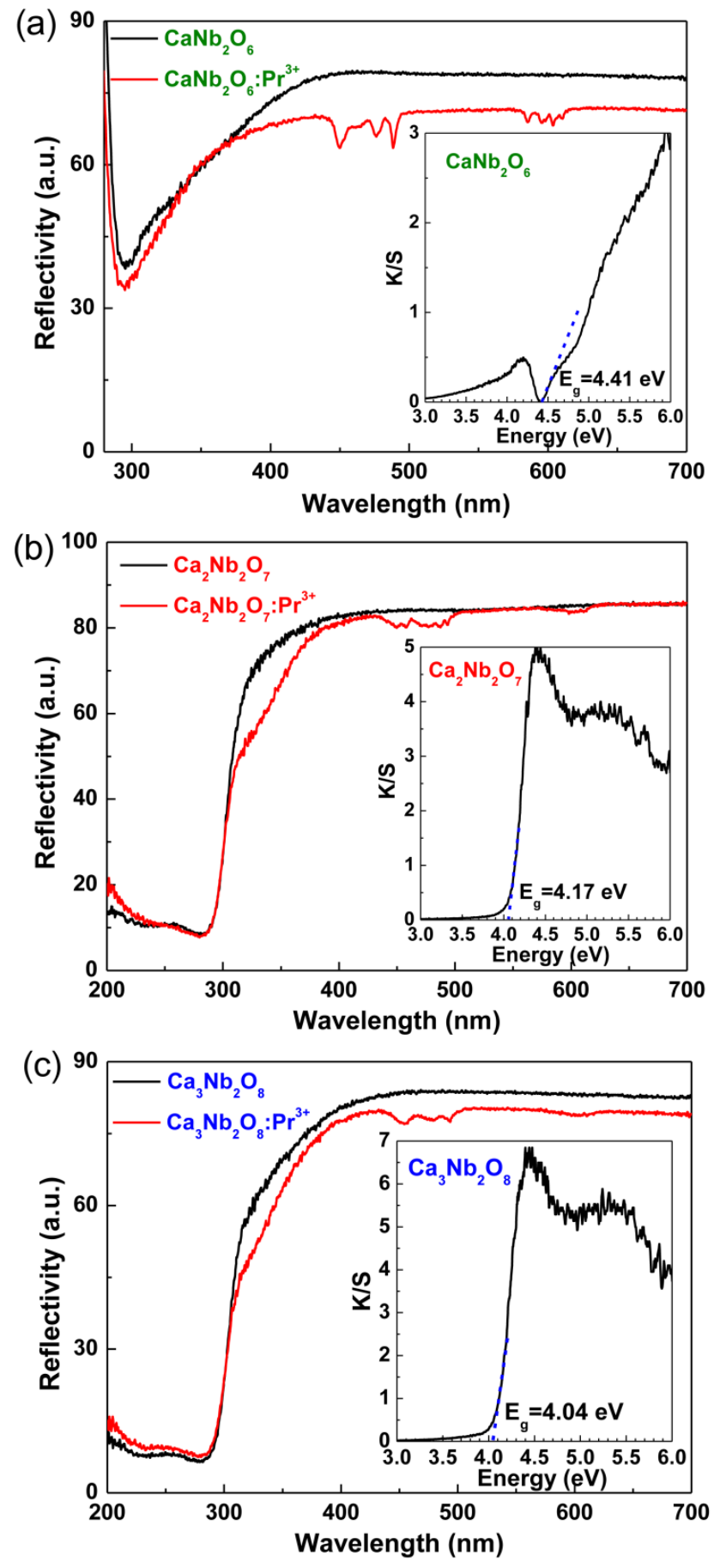

Figure S9. Diffuse reflectance spectra of the calcium niobates before and after activation with $\mathrm{Pr}^{3+}$ dopants. (a) $\mathrm{CaNb}_{2} \mathrm{O}_{6}: \mathrm{Pr}^{3+}$ (o and $0.25 \mathrm{~mol} \%$ ); (b) $\mathrm{Ca}_{2} \mathrm{Nb}_{2} \mathrm{O}_{7}: \mathrm{Pr}^{3+}$ (o and o.1 mol\%); (c) $\mathrm{Ca}_{3} \mathrm{Nb}_{2} \mathrm{O}_{8}: \mathrm{Pr}^{3+}$ (o and $0.075 \mathrm{~mol} \%$ ). The broad absorption band with a short wavelength limit at around $300 \mathrm{~nm}$ and sharp peaks in the range $450-620 \mathrm{~nm}$ are corresponding to the charge transfer transition of the $\mathrm{NbO}_{6}$ group and $4 \mathrm{f}-4 \mathrm{f}$ transitions of $\mathrm{Pr}^{3+}$, respectively. Insets show the band gaps derived from the curves of K/S vs $h v$ of the hosts. ${ }^{3}$ 
(a)

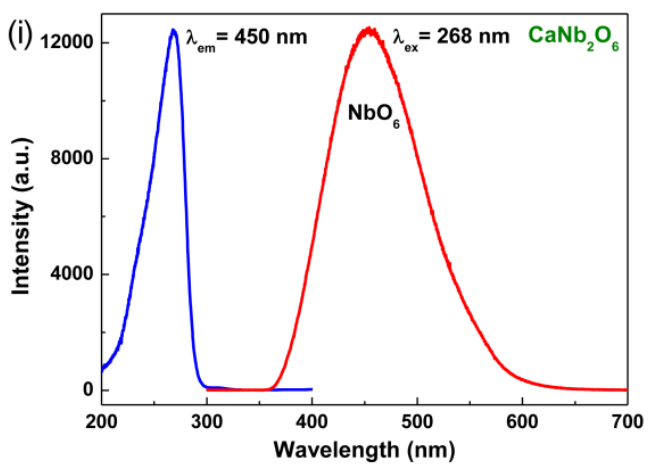

(b) (i)

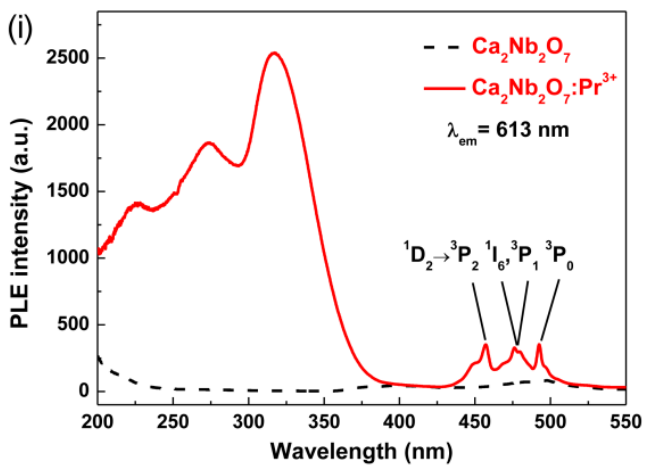

(c) (1)

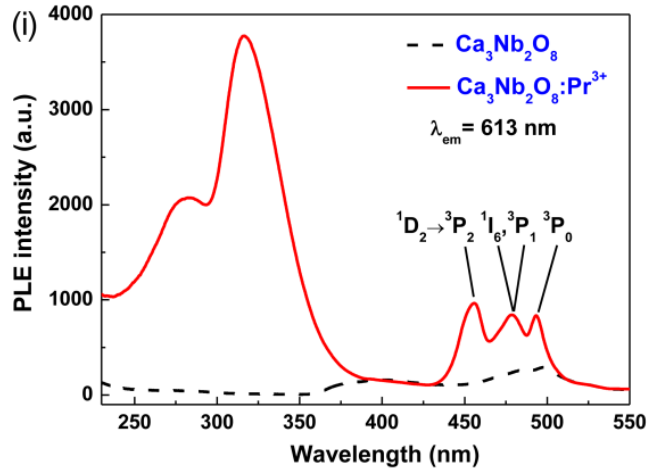

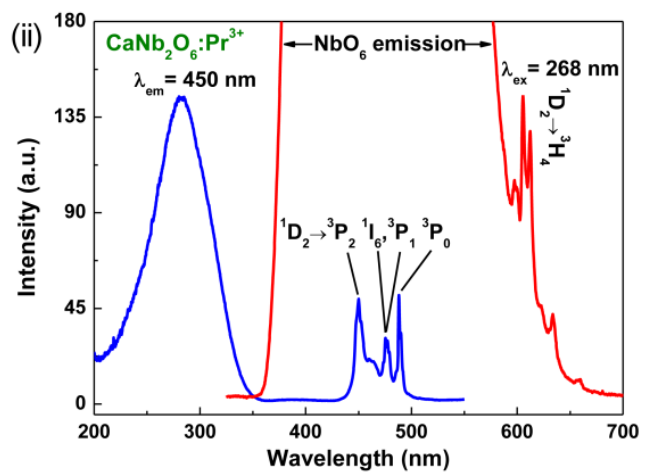
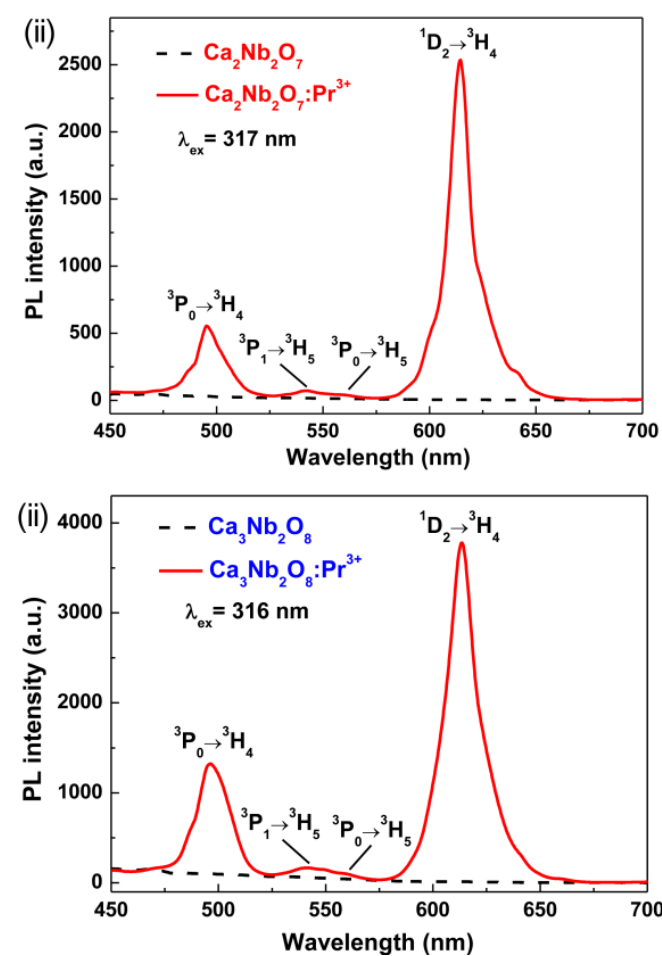

Figure Sio. PL emission and excitation spectra of the calcium niobates before and after activation with $\mathrm{Pr}^{3+}$ dopants. (a) $\mathrm{CaNb}_{2} \mathrm{O}_{6}: \mathrm{Pr}^{3+}$ (o and 0.25 mol\%); (b) $\mathrm{Ca}_{2} \mathrm{Nb}_{2} \mathrm{O}_{7}: \mathrm{Pr}^{3+}$ (o and $0.1 \mathrm{~mol} \%$ ); (c) $\mathrm{Ca}_{3} \mathrm{Nb}_{2} \mathrm{O}_{8}: \mathrm{Pr}^{3+}$ (o and $0.075 \mathrm{~mol} \%$ ).

\section{References for Supporting Information}

(1) Chen, R. Glow curves with general order kinetics. J. Electrochem. Soc. 1969, 116, 1254-1257.

(2) Levin, I.; Chan, J. Y.; Geyer, R. G.; Maslar, J. E.; Vanderah, T. A. Cation ordering types and dielectric properties in the complex perovskite $\mathrm{Ca}\left(\mathrm{Ca}_{1 / 3} \mathrm{Nb}_{2 / 3}\right) \mathrm{O}_{3}$. J. Solid State Chem. 2001, 156, 122-134.

(3) Kortüm, G.; Braun, W.; Herzog, D. C. G. Principles and techniques of diffuse-reflectance spectroscopy. Angew. Chem. Int. Ed. 1963, 2, 333-341. 